\title{
INOVAÇÃO NA SALA DE AULA: COMO A INOVAÇÃO DISRUPTIVA MUDA A FORMA DE APRENDER.
}

Ana Beatriz Simões (IFFLUMINENSE/ PPGL- UERJ)

Vivian Martins (IFRJ/PROPED- UERJ)

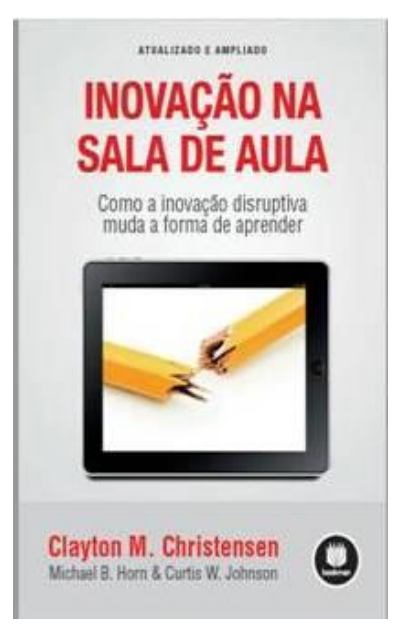

CHRISTENSEN, Clayton M; HORN, Michael B.; JOHNSON, Curtis W. Inovação na sala de aula: como a inovação disruptiva muda a forma de aprender. Tradução: Rodrigo Sardenberg. Ed. atual. e ampl. Porto Alegre: Bookman, 2012.

A obra "Inovação na sala de aula: como a inovação disruptiva muda a forma de aprender", de Clayton Christensen, Michael B. Horn e Curtis W. Johnson, é, à primeira vista, um intrigante e revolucionário volume a respeito do sistema educacional americano. Seu título materializa um efeito de manualização do êxito dos processos de aprendizagem, prioritariamente ancorado em diferentes estratégias mercadológicas ${ }^{1}$ apresentadas ao longo do livro.

Inovação na sala de aula" surge da inquietação dos autores em perceber a escola pública estadunidense como local desinteressante aos alunos, que apresenta baixos resultados em avaliações oficiais e é resistente a melhorias, apesar de altos investimentos governamentais. Diante deste cenário educacional, o ensejo em romper com práticas "monolíticas" de ensino, nas quais o professor é o detentor do saber e o transmite de modo único aos alunos, meros espectadores do processo, é materializado na teoria da disrupção.

A metodologia de suporte ao processo de inovação de ruptura, em que um produto ou serviço, altamente promissor, introduzido em um campo econômico é capaz de romper com toda a lógica consumidora, como é o caso dos celulares conectados à Internet, é cristalizada em lentes

\footnotetext{
1 Curiosamente, a obra é catalogada na seguinte categoria: “1. Administração- inovação nos negócios" (cf.ficha catalográfica), fato este que confirma a transposição das ideias mercadológicas dos autores ao sistema educacional.
} 
examinadoras ajustadas externamente ao espaço escolar. Desse modo, os autores assumem o olhar externo à educação pública como uma qualidade para realizarem a pesquisa na área, reafirmando a necessidade de estar de fora do processo para conduzir uma pesquisa confiável. O propósito de utilizar as "lentes" examinadoras a fim de compreender um fenômeno que se apresenta é compreensível, mas demonstra a incompletude do discurso de um pesquisador que não integra essa área do conhecimento, que pode não estar autorizado a problematizar o campo, pelo fato de não estar inserido na realidade que se apresenta.

Inicialmente, Christensen, Horn e Johnson (2012) debruçam-se por refletir sobre o papel de professores e alunos no sistema de ensino contemporâneo, mencionando como as aulas tradicionais são desinteressantes para os alunos. Diante desse panorama, os autores afirmam que a inclusão da tecnologia em sala é uma profícua proposta para que esse processo possa ser revertido. Os autores fundamentam a proposta de ação na customização e na centralidade no aluno, de maneira os diferentes saberes dos discentes sejam compreendidos e potencializados por seus professores. Como referencial teórico, citam Gardner (1995), a partir da teoria das Inteligências Múltiplas.

Ao longo da obra, os autores questionam de que modo é possível propiciar o ensino customizado a cada aluno e, por tal motivo, a modularidade como proposta: "A modularidade proporciona a customização, por isso a solução é avançar para uma estrutura modular nas escolas" (CHRISTENSEN; HORN; JOHNSON, 2012, p. 3-4). Os termos interdependência e modularidade são debatidos pelos autores, que apresentam a modularidade como a proposição curricular na qual os módulos de conhecimento se ajustam e funcionam em formatos combinados, podendo ser desenvolvidos em grupos independentes.

Em suma, as demais propostas apresentadas são relacionadas ao impacto dos primeiros anos sobre o sucesso dos alunos, sobre os quais os autores ressaltam a importância da eficiência na pré-escola para facilitar a tarefa das instituições de ensino; ao aprendizado baseado em computadores como uma força disruptiva "ao modo monolítico de instrução pelo professor" (CHRISTENSEN; HORN; JOHNSON, 2012, p. 101); e ao aperfeiçoamento das pesquisas em educação, onde os autores formulam “prescrições" (p. 159), já que "o paradigma existente força os pesquisadores a concluir seu trabalho quando ele chega tão somente à metade" (p. 157), prevendo quais ações levarão à melhoria do desempenho das escolas.

Com o propósito de sintetizar os principais eixos presentes no livro, os autores, no último capítulo, proferem algumas mensagens: a primeira baseia-se na crença de que poucas reformas se direcionam a compreender as singularidades dos alunos e suas dificuldades e a tese progressiva 
contida no projeto disruptor mercadológico abarca este panorama discente numa tentativa de progresso. Em seguida, releva-se que o embate "frontal" dos reformadores escolares é um ato falho e que estes precisam encontrar na teoria disruptiva para infiltrar-se, aos poucos, no sistema educacional. Após, reclama-se a adoção de um sistema modular de ensino capaz de romper com a lógica monolítica de distribuição dos conteúdos; daí a emergência da ideia da customização. E, por fim, insuflam-se líderes e gestores educacionais a se utilizarem de poder e separação para a implementação do projeto inovador, que, para Christensen, Horn e Johnson (2012) ocorre com mais facilidades nos espaços privados.

A análise do livro suscitou reflexões e entrelaçamentos com outras leituras realizadas, principalmente no campo da produção do conhecimento em educação e do aprendizado baseado em computadores. Com base em duas propostas de disrupção levantadas pelos autores, será realizada uma interlocução com outras teorias e outros pensadores, em especial o diálogo sobre as pesquisas em educação, nas quais os autores afirmam ser necessário olhar a educação por meio das lentes da inovação.

Os autores questionam os métodos e a epistemologia utilizados nas pesquisas em educação, e aconselham explorar a associação entre os atributos definidores de categoria observados no "caos escolar público" e centrar-se no que realmente importa, ou seja, no geral e regular (CHRISTENSEN; HORN; JOHNSON, 2012). O que não importa é "escondido", silenciado, borrado, o que aparta dos cotidianos suas riquezas, singularidades, imprevisibilidades e rebeldias (OLIVEIRA, 2003). Desta forma, pode-se perceber como os pressupostos assumidos pelos autores de "Inovação na Sala de Aula" entram em conflito com as pesquisas com os cotidianos (ALVES, 2008). Oliveira (2003) adverte que a compreensão dos cotidianos escolares, pela lógica galileonewtoniana na busca por regularidades e direcionada ao controle do real, apaga, silencia e retira o não controlável, o errado, o desvio e o qualifica como o fracasso, o não relevante ao campo de pesquisa.

A respeito da generalização almejada pelas investigações baseadas no rigor dito científico, Santos (2000) acrescenta que a necessidade da universalização torna a aferição, a comprovação e a testagem de dados ações motes à elaboração de leis gerais, aplicadas aos mais diversos eventos da realidade. Para Oliveira (2003), as práticas cotidianas fogem a quantificações e controle, considerando que estes cotidianos são formados por usos, táticas e criações, com regras e linguagens construídas em ato. Tais atos são fundantes para a constituição das pesquisas com os cotidianos, que apresentam um olhar direcionado para a investigação das artes de fazer e das invenções dos praticantes, que apresentam lógicas operatórias únicas e um saberfazer múltiplo e 
complexo. Desta forma, apresentamos como as pesquisas em educação podem assumir metodologias diversas, sem, necessariamente, perder em qualidade e efetividade, como é corroborado por Christensen, Horn e Johnson (2012).

A leitura crítica do livro é recomendada aos profissionais da educação que estejam interessados em reflexões contemporâneas sobre metodologias no processo de ensino e aprendizagem. Aos estudiosos da cibercultura, das tecnologias educacionais, da educação online, da didática e das diversas áreas educacionais que conversem com a temática. Alguns pontos do livro são interessantes e podem ser observados com atenção para a concepção de propostas inovadoras, como o uso de interfaces tecnológicas em sala de aula e a proposta de uma disrupção, que etimologicamente pressupõe quebra, ruptura, noção cara também à cibercultura. Entretanto, o viés mercadológico e produtivista encarnado em toda a obra subsidia ações incoerentes com a proposta de uma educação centrada no aluno, tendo em vista as inúmeras menções a respeito dos custos que tal processo proporciona.

Em síntese, a educação não pode ser compreendida como um custo, mas como um investimento. Olhar para uma área de crucial importância para a sociedade com um viés exclusivamente mercadológico, do lucro e da redução de gastos, visando somente às exigências do mercado, de otimização e de economia próspera, é desqualificar as pluralidades culturais e os cotidianos que se apresentam nas escolas públicas. Não se pretende, no entanto, apartar os saberes advindos da esfera mercadológica, já que estes podem ser também legitimados. A questão é pautarse apenas neles e desconsiderar o que os cotidianos escolares nos revelam.

\section{REFERÊNCIAS}

ALVES, Nilda. Decifrando o pergaminho: o cotidiano das escolas nas lógicas das redes cotidianas. In: OLIVEIRA, Inês B.; ALVES, Nilda. (Orgs.). Pesquisa nos/dos/com os cotidianos das escolas. $3^{\text {a }}$ ed. Petrópolis: DP\&A, 2008. p.13-38.

CHRISTENSEN, Clayton M; HORN, Michael B.; JOHNSON, Curtis W. Inovação na sala de aula: como a inovação disruptiva muda a forma de aprender. Tradução: Rodrigo Sardenberg. - Ed. atual./ampl. - Porto Alegre: Bookman, 2012.

GARDNER, Howard. Inteligências múltiplas: a teoria na prática. Tradução Maria Adriana Véronesee. Porto Alegre: Artmed, 1995.

OLIVEIRA, I. B.. Currículos Praticados: entre a regulação e a emancipação. 1. ed. Rio de Janeiro: DP\&A Editora, 2003. v. 1. $152 \mathrm{p}$.

SANTOS, Boaventura S. A crítica da razão indolente: contra o desperdício de experiência. São Paulo: Cortez, 2000. 


\section{RESUMO}

Esta resenha destina-se a apresentar a obra "Inovação na sala de aula: como a inovação disruptiva muda a forma de aprender", de Cleyton Christensen, Michael B. Horn e Curtis W. Johnson. Discute-se o ensejo dos autores em aplicar a teoria da disrupção, oriunda da esfera mercadológica, ao espaço escolar, a fim de que se contemple o êxito dos processos de ensino-aprendizagem no sistema público estadunidense. Além disso, realiza-se uma comparação entre a metodologia proposta pelos autores e as pesquisas dos/nos/com os cotidianos escolares. Por meio deste embasamento teórico, criticam-se não somente a postura externa dos autores aos fenômenos escolares em seu percurso de pesquisa, como também a imposição da necessidade de quantificação e controle do espaço educacional.

Palavras-chave: Disrupção; inovação educacional, cotidianos escolares.

\section{ABSTRACT}

This review is intended to present the book "Innovation in the Classroom: How Disruptive Innovation Changes the Way of Learning" by Cleyton Christensen, Michael B. Horn and Curtis W. Johnson. We discuss the authors' intention to apply the theory of disruption, originating from the market sphere, to the school space, in order to contemplate the success of the teaching-learning processes in the US public system. In addition, a comparison is made between the methodology proposed by the authors and the researches of / us / with the school everyday. By means of this theoretical foundation, we criticize not only the external position of the authors to school phenomena in their research, but also the imposition of the need for quantification and control of the educational space.

Keywords: Disruption; educational innovation, school everyday.

\section{RESUMEN}

Esta revisión se destina a presentar la obra "Innovación en el aula: cómo la innovación disruptiva cambia la forma de aprender", de Cleyton Christensen, Michael B. Horn y Curtis W. Johnson. Se discute la ocasión de los autores en aplicar la teoría de la disrupción, oriunda de la esfera mercadológica, al espacio escolar, a fin de que se contemple el éxito de los procesos de enseñanza-aprendizaje en el sistema público estadounidense. Además, se realiza una comparación entre la metodología propuesta por los autores y las investigaciones de los / en los / con los cotidianos escolares. Por medio de este aporte teórico, se critican no sólo la postura externa de los autores a los fenómenos escolares en su recorrido de investigación, sino también la imposición de la necesidad de cuantificación y control del espacio educativo.

Palabras clave: Disrupción; innovación educativa, cotidianos escolares.

Submetido e Aprovado em Outubro de 2019 